\title{
Cultivation of the rule consciousness of Chinese citizens in the new media era
}

\author{
Andong Shu* \\ College of Marxism, Wuhan University of Technology, Wuhan, Hubei, China. \\ tbhka@hotmail.com \\ ${ }^{*}$ Corresponding author
}

Keywords: Citizen, Rule consciousness, Cultivation.

\begin{abstract}
In the pursuit of building a beautiful and harmonious society, we sometimes regret to find that the public rules cannot get respect or maintenance from citizens in some degree, even they are the most basic ones. On the issue of rule consciousness of citizens, there are many social phenomenons that the rules are ignored, violated and even destroyed. Firstly, this paper defines several relevant concepts of the rule consciousness of citizens; Secondly, it analyzes the current situation of Chinese citizen rule consciousness, trying to find out the existing problems. What's more, on this basis, how to cultivate the rule consciousness of citizens are elaborated from the following three aspects: strengthening the education of citizen rule consciousness, creating a good environment and making full use of new media channels.
\end{abstract}

\section{Introduction}

The term citizen refers to a person who has the nationality of a country and who enjoys rights and undertake obligations according to the laws of that country. The Constitution of the People's Republic of China states: "All people with the nationality of the People's Republic of China are citizens of the People's Republic of China. Citizens of the People's Republic of China are equal according to the law. The country respects and protects human rights. Any citizen enjoys the rights stipulated by the Constitution and the law, at the same time, citizens must undertake their obligations according to the Constitution and the law."

Then we can say that the rule consciousness of citizens means that citizens consciously follow all kinds of public rules and regulations formed and formulated in society, consciously follow the law, and then transform the external compulsory of the rules into internal conscious behaviors, finally form a good habit which can be a guide to your behavior and activity.

Citizen rule consciousness is the most basic and core element of civic consciousness. It is generally believed that civic awareness is a modern consciousness, which refers to the cultivation of consciousness and quality of citizens in many aspects. It is a universal public consciousness formed under the modern constitutional system, and it is the self-reflection of the role as a citizen and its value and ideal of a modern society member. It contains three aspects: Citizen's subjective consciousness, citizens' rights awareness, and citizens' social responsibility consciousness.

\section{Status quo}

\subsection{Challenge rules}

The behavior of challenging rules stems from the lack of understanding of the importance of the rules. Rules guide People's behavior. Thus people need to know the content and importance of the rules in advance to make a behavior that conforms to the rules. Without an understanding of the content of the rules, it is possible for citizens to make an act that is repulsive to the rules. It can be said that the development of China in the past hundred years and the benefits people have gained are mainly based on the questioning of existing rules. Conversely, this success has led to the confidence of challenging 
the rules of citizens. By observing and imitating the attitudes of existing rules in society, individuals find a broader basis for their challenging of the rules and are optimistic about the consequences of it.

\subsection{Digest rules}

The phenomenon of digesting rules and the unspoken rules is becoming more and more rampant with the continuous development of China's economy. Many people think that if they do not follow the unspoken rules, tasks can't be completed on time, and it will be detrimental to their personal interests. The unspoken rules exist in many fields, for example: commercial bribery in the economy, historical rules in politics, history and face in the social field, and the diversified hidden rules in entertainment activities, including money transactions and sexual transactions. In these fields, if you do not follow the so-called hidden rules or unspoken rules, you might be squeezed out.

The prevalence of unspoken rules in society is not conducive to the cultivation and improvement of citizens' rule consciousness, and it is not conducive to the stability and development of society.

\subsection{Confront rules}

Confronting rules means that the citizens cannot use the rules to seek justice when facing the situation that the improper rules may bring harm to them. In contrast, they choose to use some extreme measures such as violence to defend their rights. However, it is a pity that such behaviors often do not achieve the results they expect, and even bring worse and longer-lasting harm to them. On the one hand, the liberation from thousands of years of slavery has not yet formed a deep-rooted sense of modern rules. Once in a state of stress treated by unreasonable rules, it will return to the most primitive jungle rules. Violence, the "weapon of the weak", maintains its legitimate interests at the expense of life. On the other hand, when people are hurt by specific unreasonable rules, because of the narrow vision, they cannot go beyond the specific rules to see the more general rules, and they cannot jump out of the specific rules to see that these unreasonable rules can be checked and balanced. Helplessly, they do nothing, either to be tolerate or violent.

\section{Cultivation}

\subsection{Education}

Education plays an important role in the cultivation of rule consciousness, and only by the joint efforts of schools, families and individuals can we ensure the continuous improvement of citizen's rule consciousness.

First of all, we must pay attention to family education. Parents are the first teachers of their children and have a great influence on their early education. Incontrovertibly, parents should attach significance to informing their children of the fact that they are ought to respect and follow rules.

Furthermore, Schools should pay more attention to cultivating students' awareness of rules, and make students obey the law. Students should always be taught to adhere to the minimum standards of human life and related rules. At the same time, it cannot be ignored for schools to strengthen students' legal awareness. Anyway, it is vital for schools to teach students how to behave acceptably and become a qualified citizen.

Last but not the least, as individuals, we must study theoretical knowledge conscientiously, participate in practical activities actively, and learn to protect public property in public places, protect the environment. Every one of us should strictly ask ourselves to be a qualified citizen and contribute to the modernization drive of our country.

\subsection{Environment}

The cultivation of citizen rule awareness not only depends on individual efforts, but also on a certain social environment and atmosphere, because people can be affected by the social environment. Therefore, we should create a good social atmosphere for the cultivation of citizen rule awareness.

Only in this way can the citizen's rule consciousness be continuously strengthened and positive social 
effects be made. For example, TV programs like "Impressive China", "the most beautiful rural doctors", "the most beautiful rural teachers" are excellent models to influence citizens with noble thoughts and exemplary behaviors, they should be encouraged greatly.

\subsection{New media}

New media can be used to promote social rules and knowledge. New media has become an important channel for citizens to express their wishes, vent their feelings and exchange ideas. Therefore, it is necessary to make full use of the platform of new media to raise citizens' awareness of rules. Many internet-based communication methods such as Weibo, WeChat are very helpful to bring people closer. The use of video, VR and other technologies could allow citizens to feel social events more intuitively. At the same time, the use of new media in publicity can achieve the dynamic and diversified propaganda, which may be more attractive to citizens.

\section{References}

[1] M. BİLGIN, Civil Society and Civic Consciousness, Dogus University Journal, vol. 05, pp. 59-70, 2004.

[2] N. S. Niu, Q. C. Yu, Reflection and Cultivation of Citizens' Consciousness of Rules, Journal of Guizhou Normal University (Social Science), vol. 02, pp. 49-55, 2017.

[3] C. L. Zhang, Y. M. Zuo, Construction of harmonious society and awakening of citizen rule cons ciousness, Journal of Xuzhou Institute of Technology, vol. 22, pp. 5-8, 2007.

[4] G. C. Jiao, Modern rule consciousness and social civilization, Ethics and moral Education research, vol. 01, pp. 27-36, 2006.

[5] X. J. Wang, X. K. Lv, A cultural psychological perspective on hidden rules as the habitus, Journal of Nankai (philosophy and Social Sciences edition), vol. 04, pp. 133-139, 2009.

[6] C. G. Jiang, The citizen's rule consciousness and the construction of the rule of law order, Social Science Research, vol. 01, pp. 23-39, 2008.

[7] X. H. Jia, Lack\&Fostering of Rule Consciousness of Contemporary College Students, Theory and Practice of Education, vol. 03, pp. 30-32, 2010.

[8] J. M. Liu, Cultivating rules consciousness is the intrinsic requirement of building harmonious society, The Guide of Science \& Education, vol. 11, pp. 222, 2010.

[9] L. Yang, How to cultivate the students' consciousness of the rule of citizenship, Journal of Teaching and Management, vol. 27, pp. 42-43, 2007.

[10]Z. M. Gao, Eight comments on "rule consciousness", Zhejiang Social Sciences, vol. 07, pp. 98-103, 2017. 